Denplan, part of Simplyhealth, has invited a group of nine young Denplan member dentists (under the age of 35) to join a new Next Gen Dental Group.

Over the course of the 12-month programme, Denplan will offer group members mentoring, professional leadership development and the chance to establish a like-minded network that can be called upon for advice and support.

The Next Gen Dental Group initiative aims to continue pushing private dentistry to the front of the debate about the future of healthcare, ensuring the voices of those working within the private dental sector - in particular, future young leaders - are heard

Catherine Rutland, Clinical Director at Denplan and chair of the Next Gen Dental Group, says: 'Denplan is committed to raising the profile of private dentists in policy-making, by advocating on their behalf and improving the understanding of dentistry more generally within government. Our new Next Gen Dental Group aims to provide the younger age group with an opportunity to start shaping dentistry policy agenda from the beginning of their careers.

'We're working collaboratively with the group to refine our one-year programme, so that the key focus areas really meet their needs. During our initial meeting, we had invaluable discussions informed by the groups' experiences around mentoring, career support and regulation of private practices. Together, we're looking at the best ways to support young and upcoming dentists, as well as how we can continue to effectively highlight ongoing issues affecting the profession to government.'

Denplan is delighted to welcome the following members to the Next Gen Dental Group; Richard Alexander at Greenlaw
Dental Care, Shamir Chandarana at Denta House, Gareth Crowther at Brynhyfryd Dental, Andrew Farr at Broad Street Dental, Veeren Gupta at Ferndale House Dental, Niki Keyhani at Horsham Dental Studio, Alice Martin at Lowen Dental Spa, Harbinder Singh-Dewgun at Lion House Dental Practice and Buckingham Dental, and Catherine Turner at The Walton Practice.

Dr Niki Keyhani from Horsham Dental Studio said: 'I am delighted to be a part of the Next Generation Dental Group. This is an exciting opportunity to work with other young dentists to highlight the issues impacting the sector and to shape its future around our experiences as dental professionals.

'I'm looking forward to working with colleagues to put forward new ideas and fresh approaches to the issues confronting us as a profession.'

\title{
The British Fluoridation Society appoints new Committee Member
}

The British Fluoridation Society (BFS) is pleased to announce Philip Martin BDS MDPH is joining its Executive Committee.

Dr Martin is a dental surgeon with more 40 years' experience. He owns and operates several dental practices in Leicester after acquiring his first practice in 1990.

He qualified in dentistry at the University of Liverpool and has mentored many young graduates through their first year in dentistry as a foundation dentist (FD) trainer. In addition to working in general dental practice, Dr Martin has been a Clinical Advisor to the Health Service Ombudsman since 2012

An active member of British Dental Association (BDA), Mr Martin has served as both president and chair of the East Midland branch. He is a long-standing member of Leicestershire Local Dental Committee (LDC), having previously served as chair, and represented both Leicestershire and Northampton on the General Dental Practice Committee of the BDA for two terms.

Dr Martin has also undertaken a part-time role as a clinical assistant in orthodontics to complete a Masters in Dental

Public Health.

Welcoming Dr Martin, Dr Barry Cockcroft CBE and BFS chair, said: 'This is an exciting time to be joining the BFS Executive Committee. I am delighted to welcome Philip to the team. He brings a wealth of expertise and experience to the organisation.

'The White Paper announced earlier this year, and the subsequent Health Bill currently in Parliament, has the potential to lead the way for new legislation that will aid the introduction of much-needed water fluoridation schemes that will help us to tackle avoidable dental health inequalities in the UK.'

Describing his appointment to the BFS, Dr Martin said: 'I very much look forward to working with all my Committee colleagues to advance the work of the BFS.
In 2013, non-fluoridated Leicester was the worst place in England for dental decay in 5 -year-olds, a situation which has improved only slightly.

'Consequently, I am very aware of the damage dental caries causes to our children. Community water fluoridation is the most effective way to reduce this burden of suffering and improving the oral health of our population.' 